\title{
Impact of Interference Competition on Exploration and Food Exploitation in the Ant Lasius niger
}

\author{
Vincent Fourcassié, ${ }^{1,2}$ Tristan Schmitt, ${ }^{1,2,3}$ and Claire Detrain ${ }^{3}$ \\ ${ }^{1}$ Centre de Recherches sur la Cognition Animale, UPS, Université de Toulouse, 118 route de Narbonne, \\ 31062 Toulouse Cedex 9, France \\ ${ }^{2}$ Centre de Recherches sur la Cognition Animale, CNRS, 118 route de Narbonne, 31062 Toulouse Cedex 9, France \\ ${ }^{3}$ Service d'Ecologie Sociale (CP 231), Université Libre de Bruxelles, 50 Avenue F Roosevelt, 1050 Bruxelles, Belgium \\ Correspondence should be addressed to Vincent Fourcassié, fourcass@cict.fr
}

Received 4 February 2012; Accepted 1 March 2012

Academic Editor: Felipe Andrés León Contrera

Copyright (๑) 2012 Vincent Fourcassié et al. This is an open access article distributed under the Creative Commons Attribution License, which permits unrestricted use, distribution, and reproduction in any medium, provided the original work is properly cited.

Competition acts as a major force in shaping spatially and/or temporally the foraging activity of ant colonies. Interference competition between colonies in particular is widespread in ants where it can prevent the physical access of competitors to a resource, either directly by fighting or indirectly, by segregating the colony foraging areas. Although the consequences of interference competition on ant distribution have been well studied in the literature, the behavioral mechanisms underlying interference competition have been less explored. Little is known on how ants modify their exploration patterns or the choice of a feeding place after experiencing aggressive encounters. In this paper, we show that, at the individual level, the aphid-tending ant Lasius niger reacts to the presence of an alien conspecific through direct aggressive behavior and local recruitment in the vicinity of fights. At the colony level, however, no defensive recruitment is triggered and the "risky" area where aggressive encounters occur is not specifically avoided during further exploration or food exploitation. We discuss how between-species differences in sensitivity to interference competition could be related to the spatial and temporal predictability of food resources at stake.

\section{Introduction}

Competition is generally considered as the major force structuring patterns of distribution and abundance in ant communities [1-4]. Both competition by exploitation and competition by interference can be found in ants. Exploitative competition is defined as the capacity for one species, one group, or one individual to find and exploit rapidly a potentially limited resource, thereby making it unavailable to competitors. Competition by interference on the other hand is defined as the capacity to prevent physical access to a resource, either directly by disturbing or attacking other foragers or indirectly, by delimiting a territory and excluding competitors from foraging sites [5]. Interference competition is particularly widespread in ants. Indeed, many ant species show some forms of territoriality $[6,7]$, and workers from one colony readily attack intruders from other colonies of the same $[3,8]$ or of a different species $[9,10]$.
The level of aggression displayed during interference encounters in ants can be tuned according to a variety of factors, including the species to which the competitor belongs $[11,12]$, the degree of familiarity with the competitor [7, 13-17], and the number of contestants [1821] as well as the incurred risks in terms of energy/time loss, injury or even mortality [22]. Moreover, the location at which encounters occur [23, 24], the type [20], and quality [25] of resources at stake determine the intensity of aggressive displays. Encounters with intruders can give rise to immediate and overt attacks, accompanied or not by the emission of alarm pheromone, vibrational stimuli, or specific motor displays [26] whose role is to attract nearby nestmates for assistance in excluding competitors. In some cases, individuals instead of attacking, can retreat and recruit nestmates to the location of the encounter (Oecophyla [27]; Pheidole [12, 28-30]; Atta [31]). 
Over longer time scale, competition by interference can modify the exploration pattern of ant workers which avoid the location of aggressive encounters [32]. Likewise, ants can tune their food recruitment behavior according to the risk of injury or mortality associated with a feeding place $[33,34]$. As regards the aphid tending ant Lasius niger, it is known that previous experience with food can influence their exploration behavior [35] but one does not know whether this behavior, as well as the dynamics of food exploitation, can be affected by previous experience with competitors. In this paper we studied therefore the response of Lasius niger workers to the presence of a conspecific intruder on their colony home range. First, we tested whether a defensive recruitment is triggered during heterocolonial encounters, that is, whether the workers contacting an intruder recruit nestmates, either locally, in the vicinity of the confrontation or inside the nest, to assist in subduing the intruder. Second, we investigated whether ant colonies subsequently modify their exploration and food exploitation behavior in order to avoid the locations at which encounters with an alien conspecific took place.

\section{Material and Methods}

2.1. Species Studied and Rearing Conditions. Experiments were run on three colonies of Lasius niger collected in September 2010 on the campus of the University of Brussels $\left(50.5^{\circ} \mathrm{N}\right.$ et $4.2^{\circ} \mathrm{E}$, Belgium). All four L. niger colonies collected were queenless and contained between 1,000 and 2,000 workers with brood. Colonies were placed in plastic boxes whose walls were coated with Fluon; they nested in test tubes with a water reservoir plugged with cotton at one end. Ants had also ad libitum access to test tubes filled with pure water or $0.6 \mathrm{M}$ sucrose. In addition, they were fed every two days with pieces of mealworm larvae (Tenebrio molitor). The temperature in the experimental room was maintained around $22^{\circ} \mathrm{C}$, and the room was lighted according to a $12: 12$ $\mathrm{L}: \mathrm{D}$ regime.

2.2. Experimental Setup. During the experiments, the boxes containing the colonies were connected by a T bridge (width: $2 \mathrm{~cm}$, length of each branch: $10 \mathrm{~cm}$ ) made of foam cardboard to two foraging areas (squared platforms of $6 \mathrm{~cm}$ side). The foraging areas were surrounded by Plexiglas walls (height: $2 \mathrm{~cm}$ ) coated with Fluon to prevent ants from falling off during the experiments. The bridge and foraging areas were covered with pieces of white paper that could be easily replaced so that ants could not be able to use the chemical marks left in previous trials.

2.3. Experimental Protocol. The experiment was divided into four successive phases (Figure 2). The first phase of the experiment lasted 15 minutes and consisted in the spontaneous exploration of the bridge and foraging platforms by the ants. This phase was followed by a 30minute confrontation phase in which a worker from an alien colony (always belonging to the same colony) was introduced either on the left or the right platform (the position was alternated between replicates). As for most ant species [36], nestmate recognition in L. niger is based on cuticular hydrocarbons [37], and workers generally strongly react when contacting a worker from an alien colony. At the end of the confrontation phase, all ants remaining in the setup were captured with a forceps and were placed back in their nest box. We then removed the pieces of paper covering the bridge, replaced them by new ones, and proceeded with a new 15-minute exploration phase. This way, ants could only rely on their spatial memory of the location where they encountered the worker from an alien colony. The second exploration phase was followed by a 30-minute phase of food exploitation in which a bottle cap containing $1 \mathrm{~mL}$ of a $0.6 \mathrm{M}$ sucrose solution was placed in the middle of each foraging platform. All phases of the experiment were recorded with a Panasonic WV-BP250 camcorder placed centrally above the bridge, at the level of the bifurcation leading to the two areas. The colonies were starved for two days before the beginning of each experiment. The pieces of paper covering the bridge were not changed between the different phases of an experiment. Walking workers of L. niger mark their colony home range passively, by laying cuticular compounds from footprints during exploration [38]. The bridge could thus be marked during the exploration phase. Such an area marking is known to potentiate the attack of conspecifics from other colonies by resident workers. The pieces of white paper however were changed between experiments so that ants could not be influenced in their choice of a branch by any odor left during previous experiments. Three colonies were tested and seven replicates of the experiment were run for each colony.

2.4. Data Acquisition and Statistical Analysis. We counted the flow of ants travelling towards the foraging areas on each branch of the bridge for each minute of the four phases of the experiment. In addition, we counted the number of ants on each foraging area for all phases of the experiment every 3 minutes.

To study the effect of our experimental procedure on the flow of ants on the bridge over the four phases of the experiment, we used a Generalized Linear Mixed Model (GLMM), [39] with the mean flow of ants per minute over the duration of each experimental phase as response variable and experimental phase as a fixed factor. Variation between colonies in the different phases of the experiment and variation between replicates within colonies in the flow of ants on the bridge were accounted for by considering colony and replicate nested within colony as random effect factors, respectively. We used treatment contrast to compare the flow of ants observed during the first exploration phase to those observed during the three other phases of the experiment. The statistical model was fitted with the penalized quasilikelihood method using the glmmPQL function of the MASS R package with a gamma distribution error.

In order to test whether ants had a significant preference for one of the two branches of the bridge we used a binomial test on the cumulated flow of ants on each branch (expected probability $=0.5$ ) for each replicate of the experiment. To compare the choice of the ants in the different phases of 


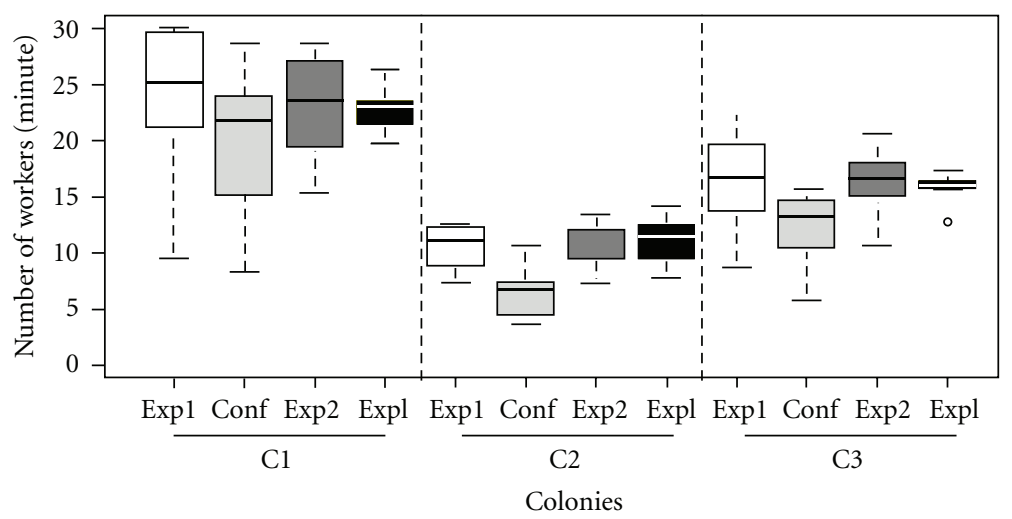

FIGURE 1: Mean flow of workers exiting the nest per minute for the different phases of the experiment and the different colonies $($ Exp $1=$ first exploration phase, Conf $=$ confrontation phase, $\operatorname{Exp} 2=$ second exploration phase, Expl $=$ food exploitation phase) and the different colonies $(\mathrm{C} 1, \mathrm{C} 2, \mathrm{C} 3) . N=7$ replicates per colony.

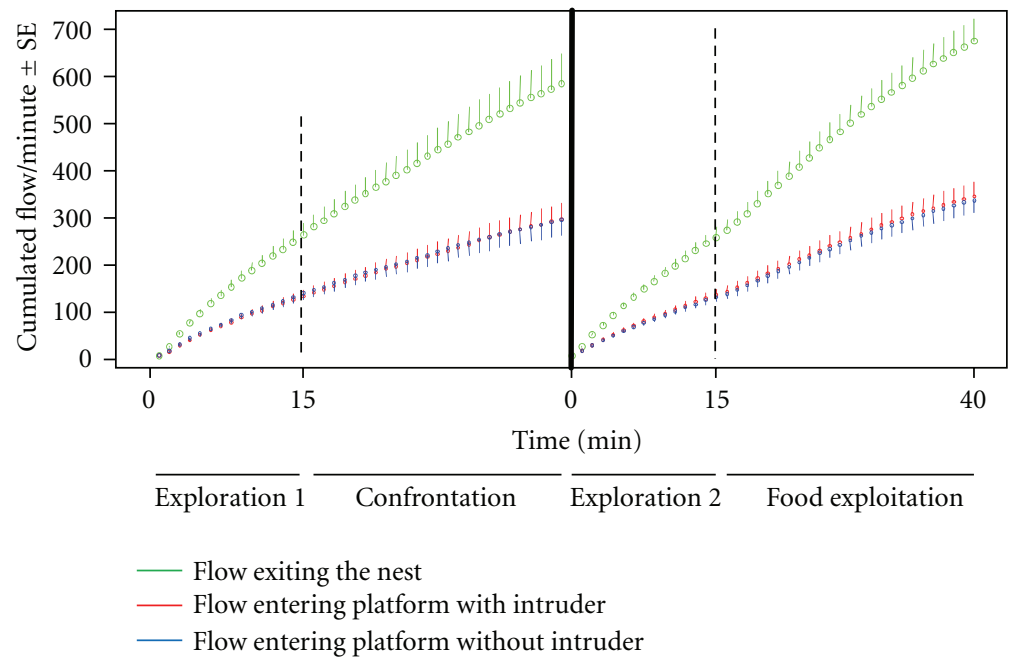

FIGURE 2: Cumulated flow of ants exiting the nest and on each branch of the bridge as a function of time (mean + SE for the flow exiting the nest and the branch where the alien worker was introduced in the confrontation phase, mean $-\mathrm{SE}$ for the other branch) $N=21$ replicates.

the experiment we computed for each phase the number of replicates in which a given percentage of the total flow of ants was observed on the branch of the bridge leading to the platform where the alien ant was introduced in the confrontation phase. A $\chi^{2}$ test for heterogeneity was then used to compare the distributions. Finally, we examined the sign of the change in the proportion of the total flow of ants exiting the nest towards the risky platform following the exposure to an alien worker. To do so we used a Student's paired $t$-test to compare, within each replicate of the experiment, the proportion of ants choosing the "risky" branch (leading to the platform where the alien worker was introduced in the confrontation phase) between the first exploration phase and each other phases of the experiment.

All statistical analyses were run with $\mathrm{R}$ version 2.13.0 (R Foundation for Statistical Computing, Vienna, Austria, http://www.r-project.org/).

\section{Results}

There was an effect of both the phase of the experiment and of the colony on the activity level of the colonies. The mean flow of ants per minute exiting the nest was indeed different among the four different phases of the experiment (Figure 1): the flow observed during the first exploration phase was significantly higher than that observed during the confrontation phase $(t=3.885, \mathrm{df}=60, P<0.001)$, but not significantly different to that observed during the second exploration phase $(t=0.261, \mathrm{df}=60, P>0.05)$ or the food exploitation phase $(t=0.377, \mathrm{df}=60, P>0.05)$. Variation between colonies in the different phases of the experiment was more than four times as important as variation between replicates within colonies. As can be seen in Figure 1, the flow of ants observed in colony 2 was always lower, whatever the phase, than in colony 1 or 3 . 
In 12 out of 21 replicates, ants did not express a significant preference for one of the branch of the bridge (binomial test, $P>0.05$ ) during the first exploration phase. In the nine replicates where they expressed a significant preference for a branch, the right branch of the bridge was always chosen. However, this did not induce a systematic orientation bias for the other phases of the experiment since the branch where the alien worker was introduced was alternatively positioned on the right or left side.

The introduction of an alien worker on one platform during the confrontation phase induced neither an increase nor a decrease in the mean flow of ants per minute towards this "risky" area (Figure 2). In 11 out of 21 replicates, ants expressed a significant preference for one branch of the bridge (binomial test, $P<0.05$ ). The branch leading to the platform where the alien worker was introduced was chosen in 6 replicates out of these 11 replicates. Overall, the frequency distribution of choice observed during the confrontation phase did not differ from that observed in the first exploration phase $\left(\chi^{2}=5.46, \mathrm{df}=3, P=0.14\right)$. Within each replicate, however, there was a slight but significant decrease in the proportion of ants choosing the branch leading to the risky platform $(t=-2.718, P=0.013)$.

During the second exploration phase that followed the confrontation phase, ants did not attempt to avoid the branch where the alien worker had been introduced. The mean flow of ants per minute on the two branches of the bridge was about the same as in the first exploration phase (Figure 2). Ants chose preferentially one branch of the bridge in six replicates out of 21 (binomial test, $P<0.005$ ). Only in 2 replicates out of these 6 replicates ants chose the branch where the alien worker had been introduced. Overall, the frequency distribution of choice observed during the second exploration phase did not differ from that observed in the first exploration phase $\left(\chi^{2}=1.59\right.$, $\left.\mathrm{df}=3, P=0.66\right)$. Compared to the choice of the ants in the first exploration phase, there was no significant difference in the percentage of ants choosing the branch leading to the risky platform $(t=-1.303, P=0.207)$. Therefore, the choice of a branch in the second exploration phase was not influenced by the location where the agonistic encounter with an alien worker occurred.

Finally, during the last food exploitation phase, the mean flow of ants per minute on each foraging platform increased in a similar way on the two branches of the bridge (Figure 2). In 17 replicates out of 21, ants expressed a significant preference for one branch, in eight replicates they preferred the branch where the alien worker was previously introduced, and in nine replicates they preferred the other branch. Collective choices of one branch were more frequently observed during food exploitation than during the other phases of the experiment: this is an expected outcome of the amplifying properties of trail recruitment towards a food source [40]. Overall, the frequency distribution of choice observed during the exploitation phase did not differ from that observed in the first exploration phase $\left(\chi^{2}=56.07\right.$, df $=3, P=0.11)$. Compared to the choice of the ants in the first exploration phase, there was no significant difference in the percentage of ants choosing the branch leading to the risky platform $(t=0.683, P=0.502)$.

As regards to the occupancy level of foraging areas, it deeply varied with the phase of the experiment (Figure 4). The number of ants on each area increased rapidly at the beginning of the first exploration phase, up to the 10th minute where it began to slightly decrease. During the confrontation phase, while the number of ants remained stable on the "safe" area, it increased steeply on the area where the alien ant was introduced and peaked at the 6th minute. On average, ants were more numerous on the risky platform than on the safe one during the confrontation phase. Actually, when an alien ant was present, a local recruitment was launched: while the intruder was seized by a few resident ants, it was attacked several times by other nestmates. During the second exploration phase, the same level of occupancy as during the first exploration phase was observed for both areas. Finally, the introduction of a food source initially induced a slight increase of the number of foragers which was similar over the two foraging areas and remained stable until the end of the experiment.

The frequency distribution of replicates as a function of the proportion of their foragers on the risky platform (Figure 5) was significantly different between the first exploration phase and the confrontation phase $\left(\chi^{2}=24.22\right.$, df $=7, P=0.001)$ due to the local defensive recruitment induced by the presence of an intruder. On the other hand, the frequency distribution of area occupancy was not significantly different between the first and the second exploration phase $\left(\chi^{2}=5.77, \mathrm{df}=5, P=0.33\right)$ and between the first exploration phase and the exploitation phase $\left(\chi^{2}=\right.$ 3.91, $\mathrm{df}=5, P=0.56)$.

\section{Discussion}

Physical contact or interference with an alien conspecific resulted in a decrease in the flow of Lasius niger ants exiting the nest, the latter orienting themselves equally towards the risky or the safer locations (Figure 3). Therefore, workers having encountered a single alien individual on their home range did not recruit additional workers from the nest for assistance. Although L. niger workers did not launch a longrange recruitment, they did react at a local scale by increasing their number in the vicinity of agonistic encounters (Figure 4): as soon as an ant entered the risky area, it began trying to subdue the intruder. This temporarily prevented it from returning to the nest to recruit nestmates. The extended staying time of the ants on the risky area may therefore explain the absence of long-range defensive recruitment. One could argue, however, that such a defensive recruitment would be useless since the alien ant was outnumbered by resident ants, right from the beginning of its introduction on the foraging area. It would be interesting to know whether recruitment occurs in $L$. niger when cooperative defense is really useful, that is, when resident ants are outnumbered by intruder ants or when resources that can be monopolized by intruders are at stake.

After the confrontation phase, ants did not avoid the area where the encounter with the intruder took place. Unlike 

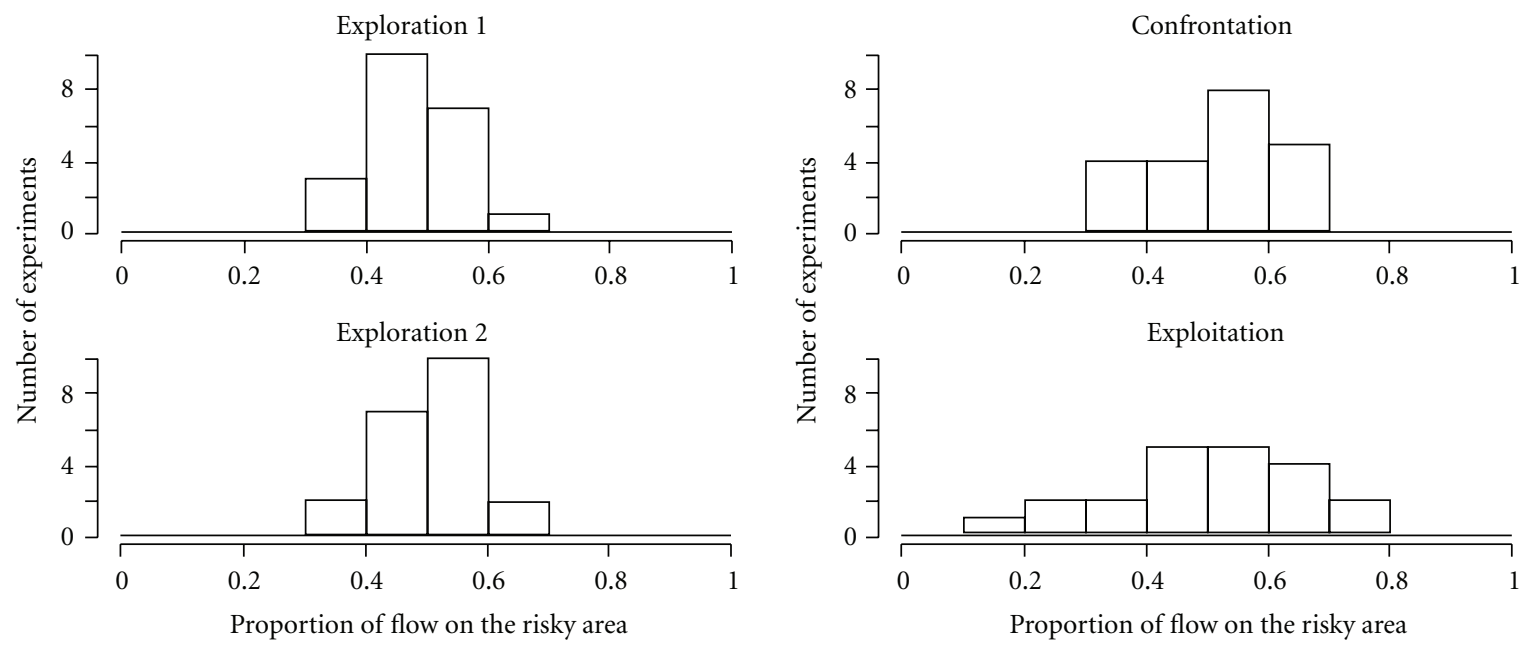

FIGURE 3: Distributions of all replicates as a function of the proportion of ants that were heading towards the area where the alien ant was introduced. The proportion values were calculated over the cumulated flows of ants observed at the end of each phase of the experiment. $N=21$ replicates.

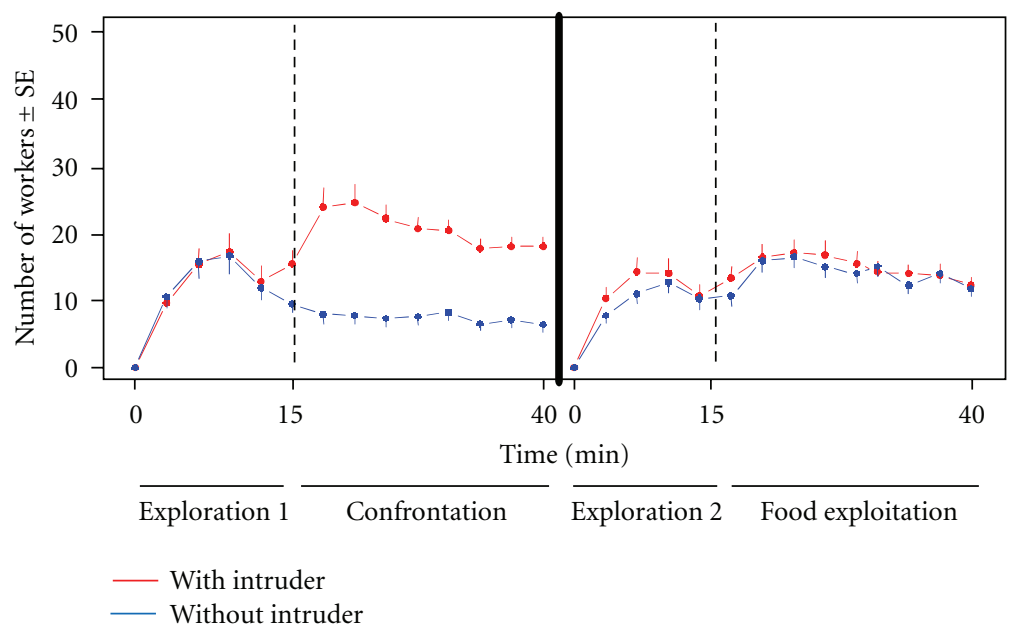

FIGURE 4: Number of ants (mean + SE for the platform where the alien worker was introduced, mean - SE for the other platform) observed every 3 minutes on each platform of the bridge as a function of time. $N=21$ replicates.

Formica xerophila workers that avoid a location where they have had a negative experience [32], L. niger colonies showed the same dynamics and pattern of exploration before and after experiencing agonistic interactions. Likewise, they did not avoid or reduce recruitment intensity towards a food source discovered on a potentially risky location where they had previously experienced aggression.

It would seem logical for ant colonies to avoid potentially dangerous areas. Therefore, one may wonder why in our experiment $L$. niger colonies failed to specifically alter their level of exploration and food exploitation after being exposed to interference competition.

First, one could argue that a single alien worker did not represent a threat high enough or that the exposure time to the threat was not long enough to elicit an avoidance response. However, in the Argentine ant Linepithema humile, a single $3 \mathrm{~min}$ encounter with a heterocolonial conspecific is enough to produce a long-lasting effect, increasing the propensity to fight in encounters up to a week later [41]. In the same way, in Lasius pallitarsis, a short encounter with a single potentially lethal enemy is enough to induce the avoidance of associated food patches even 18-24 h after the encounter occurred [33]. Thus, in our experiment, L. niger ants had ample time to perceive interference competition interactions: the intruder was not immediately killed but was physically attacked by several resident workers during the 30 minutes of the confrontation phase.

Second, one could object that ants did not have enough time to develop a spatial memory of the location where the aggressive encounter took place. L. niger workers, however, are known to have a well-performing spatial memory [42, 43]. For instance, using a T-bridge similar to our experiment, Grüter et al. [44] showed that after one single visit to a food source, most L. niger workers were able to orient to 

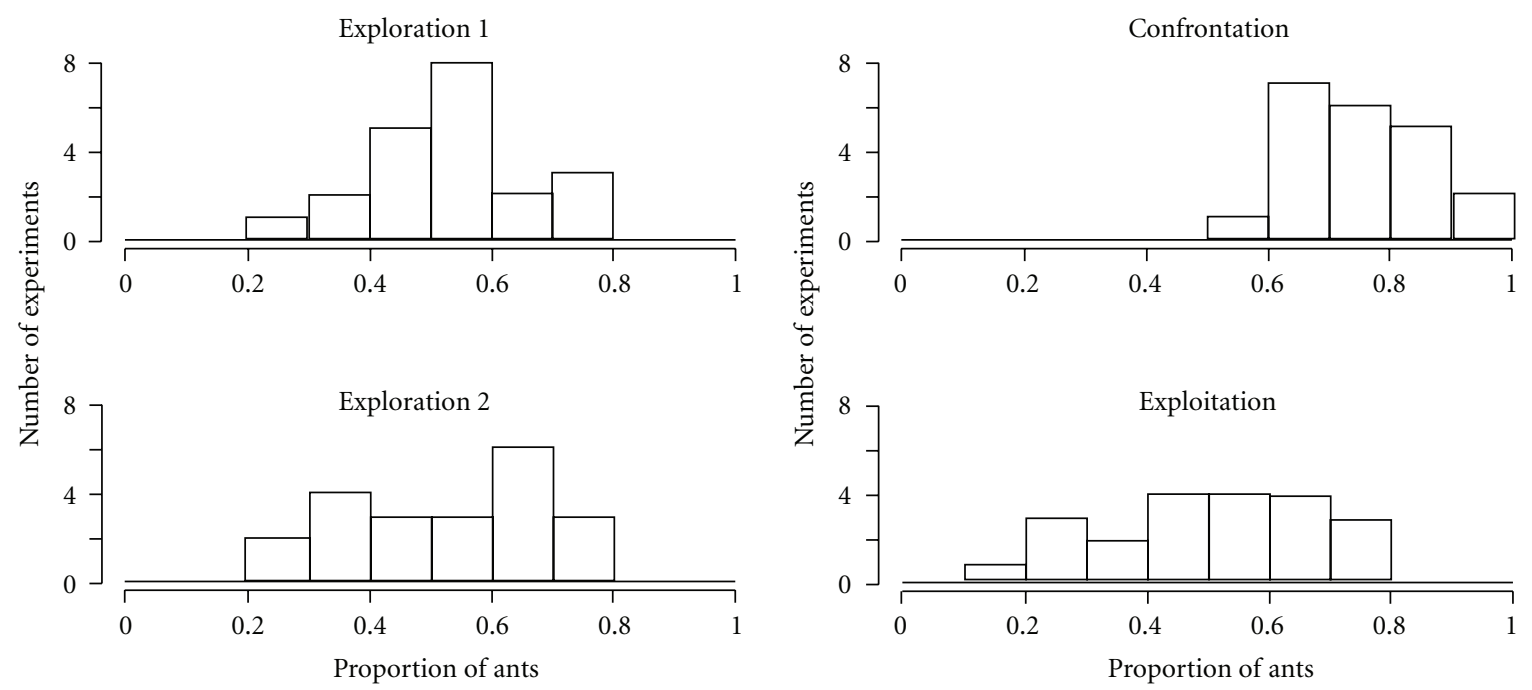

FIgURE 5: Distributions of all replicates as a function of the proportion of workers on the area where the alien ant was introduced (among all foragers present on the two areas). $N=21$ replicates.

the branch associated with the food source, only on the basis of visual landmarks.

Third, the ability of an ant species to adjust its exploratory, foraging, and defense strategies to match the surrounding competitive risks is likely to be under natural selection pressure and thus strongly correlated to its ecology [24]. Specifically, interference competition interactions may lead to distinct territorial and foraging strategies according to the characteristics of the food resources at stake. For example, temporally and spatially variable food sources such as prey or seed patches are exploited by several ant species. The ephemeral availability of such resources makes the maintenance of absolute territories costly and difficult to achieve. Therefore, a high sensitivity to competition pressure seems well suited for those ants exploiting ephemeral resources allowing them to adjust in a flexible way their exploratory/food exploitation behavior and thereby to reduce the overlap of feeding areas between competing neighbor colonies. In contrast to prey or seed patches, aphid colonies provide stable and renewable resources. Since ants continually require carbohydrates from honeydew to sustain their daily activities, aphid-tending ants such as L. niger must maintain access to such resources, even when there is an associated risk of competition. Aphid tending ants thus may prioritize the stabilization of foraged areas by being poorly sensitive to punctual interference competition interactions. Since L. niger lives in environments where contacts with competitors are inevitable, defense of aphid resources could be achieved through a local enhancement of agonistic behavior at key locations, such as the vicinity of aphid colonies or the foraging trails. When the competitive pressure becomes higher, the active recruitment of defenders from within the nest will then determine the colony ability to dominate and displace competitors or to abandon the food resource.

Since aggressive behaviours can be costly in terms of energy, time, and physical injuries, any information regarding competitive pressure should be integrated at the colony level to shape the exploratory and foraging strategies of the colony. However, our study reveals that the integration of such information can vary among ant species, $L$. niger being weakly sensitive to previous exposure to a limited interference competition. To fully understand the decisionmaking process of ant colonies, species-specific responses to agonistic stimuli will have to be investigated in different contexts, such as when the resources at stake are of different quality. Indeed, since in nature food sources vary in their spatiotemporal availability, as well as in their associated risk, colonies may have to make complex decisions: this should involve tradeoffs between the monopolization of rewarding areas under normal competition conditions and the avoidance of dangerous areas through a high spatial flexibility of their home range.

\section{Disclosure}

The authors declare that they do not have any direct financial link with any of the commercial identity mentioned in this paper.

\section{Acknowledgments}

This work was financed by a PICS exchange program (200810) between UMR CNRS 5169 (University Toulouse III) and the Unit of Social Ecology (ULB) as well as by a FRFC Grant 2.4600.09. from the Belgian National Fund for Scientific Research. D. Claire is Senior Research Associate at the Belgian National Fund for Scientific Research.

\section{References}

[1] F. R. Adler and D. M. Gordon, "Optimization, conflict, and nonoverlapping foraging ranges in ants," American Naturalist, vol. 162 , no. 5 , pp. 529-543, 2003. 
[2] A. N. Andersen and A. D. Patel, "Meat ants as dominant members of Australian ant communities: an experimental test of their influence on the foraging success and forage abundance of other species," Oecologia, vol. 98, no. 1, pp. 15-24, 1994.

[3] J. H. Fellers, "Interference and exploitation in a guild of woodland ants," Ecology, vol. 68, no. 5, pp. 1466-1478, 1987.

[4] R. Savolainen and K. Vepsalainen, "A competition hierarchy among boreal ants: impact on resource partitioning and community structure," Oikos, vol. 51, no. 2, pp. 135-155, 1988.

[5] M. Begon, J. L. Harper, and C. R. Townsend, Ecology: Individuals, Populations and Communities, Blackwell Scentific, 1996.

[6] S. C. Levings and J. F. A. Traniello, "Territoriality, nest dispersion, ant community structure in ants," Psyche, vol. 88, pp. 265-319, 1981.

[7] D. M. Gordon, Ant Encounters: Interaction Networks and Colony Behavior, Princeton University press, Princeton, NJ, USA, 2010.

[8] D. A. Grasso, A. Mori, M. Giovannotti, and F. Le Moli, "Interspecific interference behaviours by workers of the harvesting ant Messor capitatus (Hymenoptera Formicidae)," Ethology Ecology and Evolution, vol. 16, no. 3, pp. 197-207, 2004.

[9] M. L. Thomas, N. D. Tsutsui, and D. A. Holway, "Intraspecific competition influences the symmetry and intensity of aggression in the Argentine ant," Behavioral Ecology, vol. 16, no. 2, pp. 472-481, 2005.

[10] R. Boulay, J. A. Galarza, B. Chéron et al., "Intraspecific competition affects population size and resource allocation in an ant dispersing by colony fission," Ecology, vol. 91, no. 11, pp. 3312-3321, 2010.

[11] E. O. Wilson, "Enemy specification in the alarm recruitment system of an ant," Science, vol. 190, no. 4216, pp. 798-800, 1975.

[12] N. F. Carlin and A. B. Johnston, "Learned enemy specification in the defense recruitment system of an ant," Naturwissenschaften, vol. 71, no. 3, pp. 156-157, 1984.

[13] J. Heinze, S. Foitzik, A. Hippert, and B. Hölldobler, "Apparent dear-enemy phenomenon and environment-based recognition cues in the ant Leptothorax nylanderi," Ethology, vol. 102, no. 6, pp. 510-522, 1996.

[14] T. A. Langen, F. Tripet, and P. Nonacs, "The red and the black: habituation and the dear-enemy phenomenon in two desert Pheidole ants," Behavioral Ecology and Sociobiology, vol. 48, no. 4, pp. 285-292, 2000.

[15] S. Sanada-Morimura, M. Minai, M. Yokoyama, T. Hirota, T. Satoh, and Y. Obara, "Encounter-induced hostility to neighbors in the ant Pristomyrmex pungens," Behavioral Ecology, vol. 14, no. 5, pp. 713-718, 2003.

[16] R. D. Dimarco, A. G. Farji-Brener, and A. C. Premoli, "Dear enemy phenomenon in the leaf-cutting ant Acromyrmex lobicornis: behavioral and genetic evidence," Behavioral Ecology, vol. 21, no. 2, pp. 304-310, 2010.

[17] E. Van Wilgenburg, J. Clémencet, and N. D. Tsutsui, "Experience influences aggressive behaviour in the Argentine ant," Biology Letters, vol. 6, no. 2, pp. 152-155, 2010.

[18] G. Buczkowski and J. Silverman, "Context-dependent nestmate discrimination and the effect of action thresholds on exogenous cue recognition in the Argentine ant," Animal Behaviour, vol. 69, no. 3, pp. 741-749, 2005.

[19] C. J. Tanner, "Numerical assessment affects aggression and competitive ability: a team-fighting strategy for the ant Formica xerophila," Proceedings of the Royal Society B, vol. 273, no. 1602, pp. 2737-2742, 2006.

[20] C. J. Tanner, "Resource characteristics and competition affect colony and individual foraging strategies of the wood ant
Formica integroides," Ecological Entomology, vol. 33, no. 1, pp. 127-136, 2008.

[21] T. P. Batchelor and M. Briffa, "Fight tactics in wood ants: individuals in smaller groups fight harder but die faster," Proceedings of the Royal Society B, vol. 278, pp. 3243-3250, 2011.

[22] I. Scharf, T. Pamminger, and S. Foitzik, "Differential response of ant colonies to intruders: attack strategies correlate with potential threat," Ethology, vol. 117, no. 8, pp. 731-739, 2011.

[23] M. Knaden and R. Wehner, "Nest Defense and conspecific enemy recognition in the desert ant Cataglyphis fortis," Journal of Insect Behavior, vol. 16, no. 5, pp. 717-730, 2003.

[24] C. J. Tanner and F. R. Adler, "To fight or not to fight: contextdependent interspecific aggression in competing ants," Animal Behaviour, vol. 77, no. 2, pp. 297-305, 2009.

[25] R. Boulay, X. Cerdá, T. Simon, M. Roldan, and A. Hefetz, "Intraspecific competition in the ant Camponotus cruentatus: should we expect the "dear enemy" effect?" Animal Behaviour, vol. 74, no. 4, pp. 985-993, 2007.

[26] B. Hölldobler, "Multimodal signals in ant communication," Journal of Comparative Physiology A, vol. 184, no. 2, pp. 129141, 1999.

[27] B. Hölldobler and E. O. Wilson, "The multiple recruitment systems of the african weaver ant Oecophylla longinoda (Latreille) (Hymenoptera: Formicidae)," Behavioral Ecology and Sociobiology, vol. 3, no. 1, pp. 19-60, 1978.

[28] E. O. Wilson, "The organization of colony defense in the ant Pheidole dentata mayr (Hymenoptera: Formicidae)," Behavioral Ecology and Sociobiology, vol. 1, no. 1, pp. 63-81, 1976.

[29] C. Detrain and J. M. Pasteels, "Caste polyethism and collective defense in the ant, Pheidole pallidula: the outcome of quantitative differences in recruitment," Behavioral Ecology and Sociobiology, vol. 29, pp. 405-412, 1992.

[30] A. Dejean, J. Le Breton, J. P. Suzzoni, J. Orivel, and C. Saux-Moreau, "Influence of interspecific competition on the recruitment behavior and liquid food transport in the tramp ant species Pheidole megacephala," Naturwissenschaften, vol. 92, no. 7, pp. 324-327, 2005.

[31] M. E. A. Whitehouse and K. Jaffe, "Ant wars: combat strategies, territory and nest defence in the leaf- cutting ant Atta laevigata," Animal Behaviour, vol. 51, no. 6, pp. 1207-1217, 1996.

[32] C. J. Tanner, "Individual experience-based foraging can generate community territorial structure for competing ant species," Behavioral Ecology and Sociobiology, vol. 63, no. 4, pp. 591-603, 2009.

[33] P. Nonacs and L. M. Dill, "Foraging response of the ant Lasius pallitarsis to food sources with associated mortality risk," Insectes Sociaux, vol. 35, no. 3, pp. 293-303, 1988.

[34] P. Nonacs and L. M. Dill, "Mortality risk versus food quality trade-offs in ants: patch use over time," Ecological Entomology, vol. 16, no. 1, pp. 73-80, 1991.

[35] J. Le Breton and V. Fourcassié, "Information transfer during recruitment in the ant Lasius niger L. (Hymenoptera: Formicidae)," Behavioral Ecology and Sociobiology, vol. 55, pp. 242250, 2004.

[36] S. Martin and F. Drijfhout, "A review of ant cuticular hydrocarbons," Journal of Chemical Ecology, vol. 35, no. 10, pp. 1151-1161, 2009.

[37] A. Lenoir, S. Depickère, S. Devers, J. P. Christidès, and C. Detrain, "Hydrocarbons in the ant Lasius niger: from the cuticle to the nest and home range marking," Journal of chemical ecology, vol. 35, no. 8, pp. 913-921, 2009. 
[38] C. Devigne and C. Detrain, "Collective exploration and area marking in the ant Lasius niger," Insectes Sociaux, vol. 49, no. 4, pp. 357-362, 2002.

[39] J. C. Pinheiro and D. M. Bates, Mixed Effects Models in S and S-Plus, Springer, 2000.

[40] R. Beckers, J. L. Deneubourg, and S. Goss, "Trail laying behaviour during food recruitment in the ant Lasius niger (L.)," Insectes Sociaux, vol. 39, no. 1, pp. 59-72, 1992.

[41] E. Van Wilgenburg, J. Clémencet, and N. D. Tsutsui, "Experience influences aggressive behaviour in the Argentine ant," Biology Letters, vol. 6, no. 2, pp. 152-155, 2010.

[42] S. Aron, R. Beckers, J. L. Deneubourg, and J. M. Pasteels, "Memory and chemical communication in the orientation of two mass-recruiting ant species," Insectes Sociaux, vol. 40, no. 4, pp. 369-380, 1993.

[43] S. E. F. Evison, O. L. Petchey, A. P. Beckerman, and F. L. W. Ratnieks, "Combined use of pheromone trails and visual landmarks by the common garden ant Lasius niger," Behavioral Ecology and Sociobiology, vol. 63, no. 2, pp. 261-267, 2008.

[44] C. Grüter, T. J. Czackzes, and F. L. Ratnieks, "Decision making in ant foragers (Lasius niger) facing conflicting private and social information," Behavioral Ecology and Sociobiology, vol. 65, pp. 141-148, 2011. 

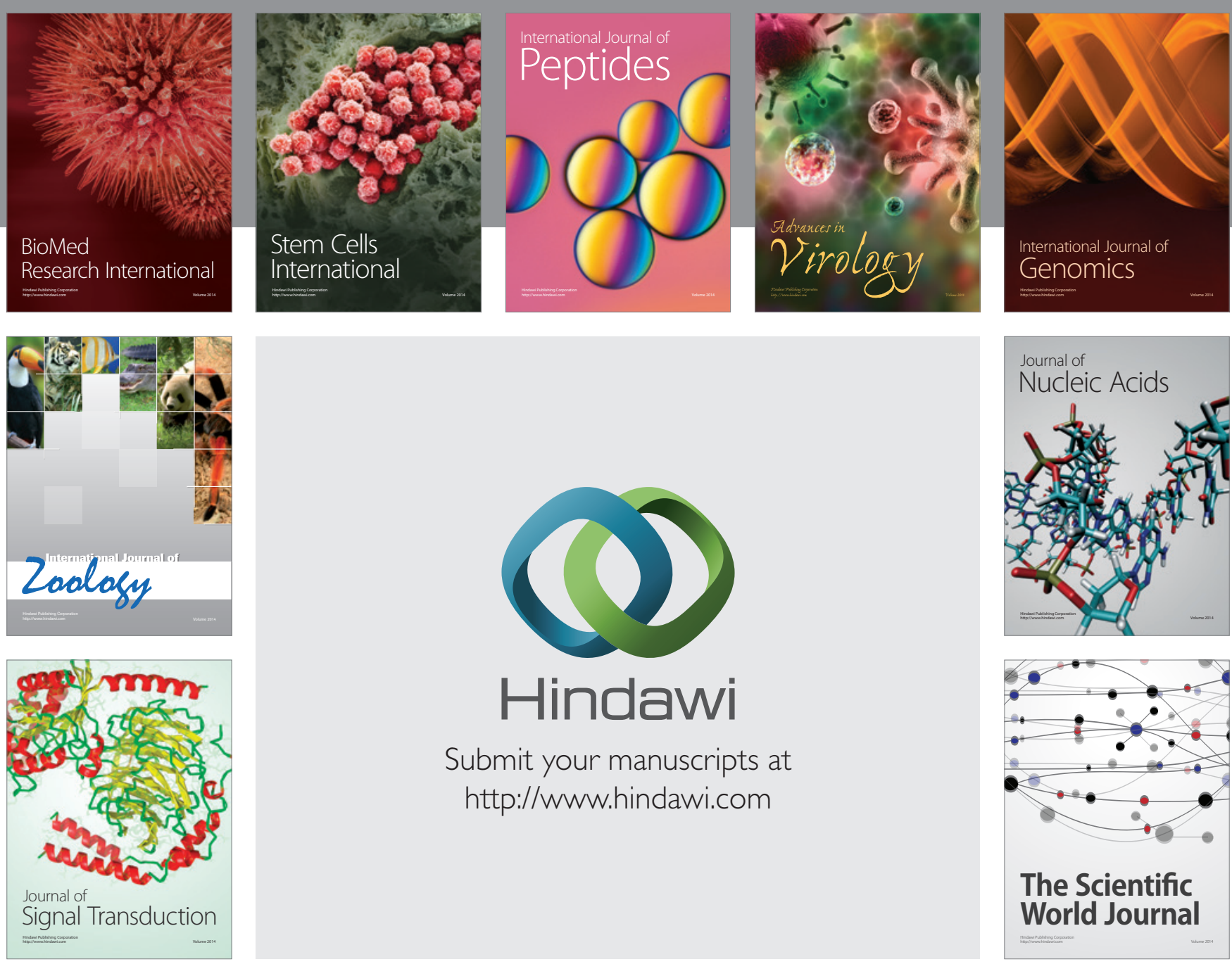

Submit your manuscripts at

http://www.hindawi.com
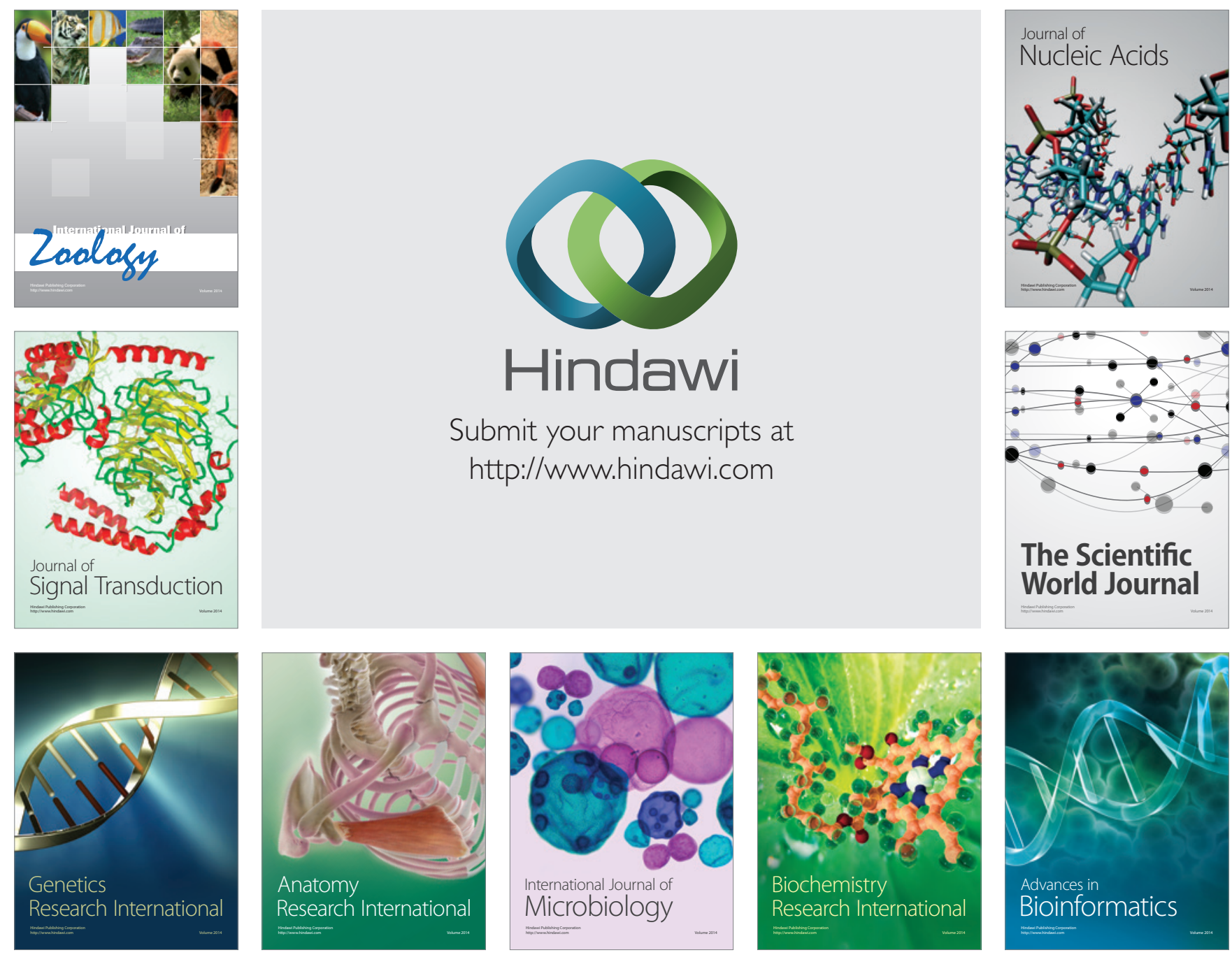

The Scientific World Journal
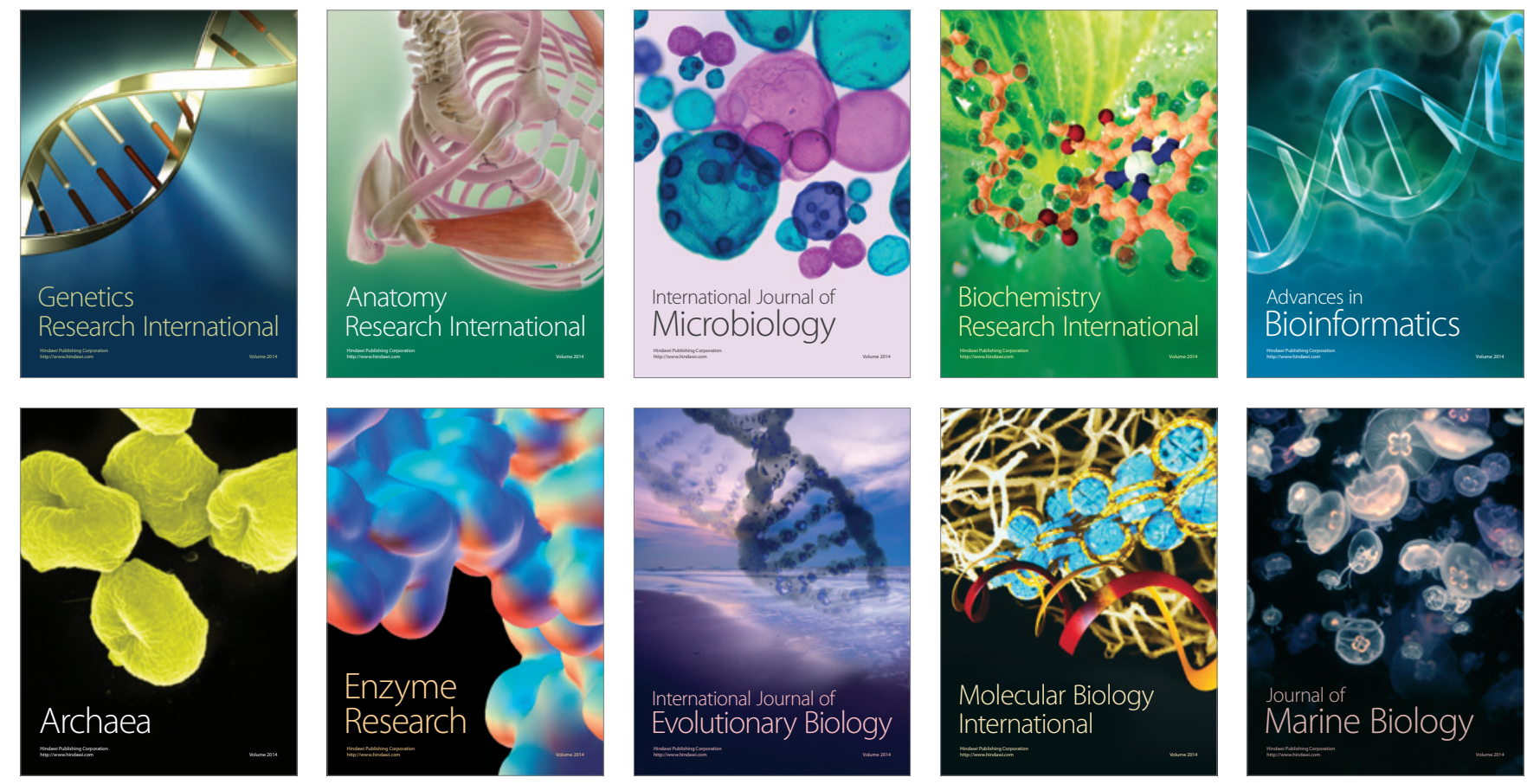